\title{
Dossiê
}

\section{DINÂMICAS DE GÊNERO E FEMINISMOS EM CONTEXTOS AFRICANOS}

\author{
Eufémia Vicente Rocha \\ Universidade de Cabo Verde, Praia, Cabo Verde \\ Miriam Steffen Vieira \\ Universidade do Vale do Rio dos Sinos, São Leopoldo, Rio Grande do Sul, Brasil
}

\begin{abstract}
O presente dossiê visa contribuir para os debates promovidos pela Revista Estudos Feministas sobre feminismos descoloniais e pós-coloniais, apresentando reflexões oriundas de estudos desenvolvidos em contextos africanos - Cabo Verde, São Tomé e Príncipe, Guiné Bissau, Angola, Moçambique e África do Sul.

Apresenta artigos de pesquisadoras e docentes vinculadas a universidades nesses países, com uma formação marcada pelo trânsito, através dos estudos de pós-graduação em universidades africanas, brasileiras e europeias; mas também, por pesquisadoras brasileiras e uma autora argentina, docentes e pós-graduandas que desenvolvem estudos em contextos africanos. Desse modo, as singularidades dos dados de campo são trabalhadas desde diferentes perspectivas teóricas e formações.

O dossiê reúne uma diversidade temática - das narrativas musicais de mulheres, ao trabalho e participação na vida pública, feminismos, homossexualidade, raça e suas interseccionalidades - e, em alguns casos, apresenta o esforço de um olhar comparativo ou beneficiado pelo contraste decorrente da pesquisa realizada em outros contextos nacionais.

No primeiro artigo, "Para além dos Feminismos: uma experiência comparada entre Guiné-Bissau e Brasil", Angela Figueiredo e Patrícia Godinho Gomes debruçam-se sobre as articulações entre gênero e raça no Brasil e em Guiné Bissau. Levando em consideração as especificidades de cada processo histórico, as autoras enfrentam o desafio de um olhar comparativo sobre esses contextos, desde a experiência comum de ex-colônias portuguesas
\end{abstract}


e, particularmente, focalizando tal percurso da perspectiva das mulheres negras, como etnicamente diferenciadas e racializadas, e seus efeitos específicos nos feminismos desenvolvidos. O texto inicia com uma reflexão teórica em torno das interseccionalidades e das distintas propostas analíticas neste âmbito para, em seguida, desenvolver um "diálogo" comparativo em consideração às experiências advindas dos dois contextos históricos e seus desdobramentos em feminismos e reconhecimentos de direitos. Sem o objetivo de fechar o debate com respostas, as autoras apresentam contribuições instigantes, tanto sobre as interseccionalidades, quanto sobre os feminismos negros e africanos daí resultantes, suas especificidades e encontros possíveis.

Esta dimensão contrastiva também emerge dos estudos elaborados pelas pósgraduadas ligadas a Programas de Pós-Graduação no Brasil, Denise Ferreira da Costa Cruz e Natalia Cabanillas, pela imersão decorrente do trabalho de campo em países africanos. Com base em uma etnografia realizada em Maputo, no período de 2011 a 2015, Denise é autora do artigo "Algumas notas sobre bonecas para mulheres "negras" em Maputo". O texto apresenta relatos de mulheres negras moçambicanas, de classe média, adultas, num olhar retrospectivo sobre as suas infâncias e as brincadeiras com as bonecas. A partir da relação com as bonecas, a autora desenvolve reflexões sobre gênero e estética negra, particularmente, em torno dos cabelos e das possibilidades que oferta ao existir das mulheres, em termos de constantes mudanças estéticas, mas também nas subjetividades. O texto encerra sugerindo um contraponto com jovens ativistas brasileiras, desde as lutas por reconhecimento, a partir da estética.

No artigo "Normalizar la existencia lesbiana", Natalia Cabanillas explora as ressonâncias entre estas dimensões de ativismo, destacando o caráter "político-sensorial" das lutas por reconhecimento, especificamente para o ativismo LGTBI na África do Sul.

Carla Indira Carvalho Semedo, depois de realizar um estudo sobre as redefinições das noções de gênero entre o grupo de batukadeiras de São Martinho Grande (llha de Santiago, Cabo Verde), no ano de 2009, prosseguiu tematizando as narrativas musicais entre cabo-verdianas em São Tomé e Príncipe. A antropóloga contribui com este dossiê a partir do artigo "Musicalidades das cabo-verdianas nas roças de São Tomé e Príncipe", apresentando as narrativas musicais de mulheres cabo-verdianas dos coletivos de Ouro Verde e Raiz di Tera como "atos de criação de espaços políticos". Estas narrativas são compreendidas pela autora, não como um domínio em separado, mas num continuum às práticas sociais, daí a riqueza da análise ao focalizar nestes espaços criativos. Ao desenvolverem temas do cotidiano e das relações de gênero, as mulheres, através das narrativas musicais e da jocosidade, encontram momentos de resistência, de crítica e de agenciamentos em meio a uma estrutura social androcêntrica.

A dimensão da agência das mulheres também foi tematizada no texto de Carla Santos de Carvalho, "Mulheres na "fornadja". Tecendo caminhos (im)possíveis para a emigração". Fornadja, em crioulo cabo-verdiano, refere-se ao espaço de produção de aguardente. $O$ estudo apresenta os efeitos sociais da emigração masculina para a ocupação desta atividade por mulheres de Ribeira da Principal, na llha de Santiago, em Cabo Verde. Primeiramente, pela ampliação da circulação das mulheres no espaço público, e, em seguida, pelas possibilidades que oferece no projeto migratório autônomo e independente destas mulheres. O trabalho é resultado de uma etnografia de longa duração, desenvolvida desde 2008.

Eurídice Furtado Monteiro, no artigo "Crioulidade, colonialidade e género: as representações de Cabo Verde", focaliza estas representações em sintonia com as construções da identidade nacional. Para tanto, dialoga com os estudos pós-coloniais e feministas, particularmente, em torno da ideia de mestiçagem.

906 Estudos Feministas, Florianópolis, 24(3): 905-907, setembro-dezembro/2016 
Por fim, Ermelinda Liberato, cientista social angolana, nos brinda com o texto " 40 anos de independência: uma reflexão em torno da condição da mulher angolana", que nos oferece uma pesquisa documental em torno das lutas sociais pelos direitos das mulheres angolanas.

Boa leitura!

[Recebido em 16/05/2016 e aceito para publicação em 18/05/2016] 